\title{
Effects of Hormone Replacement Therapy and Aging on Cognition: Evidence for Executive Dysfunction
}

\section{Domonick J. Wegesin \& Yaakov Stern}

To cite this article: Domonick J. Wegesin \& Yaakov Stern (2007) Effects of Hormone Replacement Therapy and Aging on Cognition: Evidence for Executive Dysfunction, Aging, Neuropsychology, and Cognition, 14:3, 301-328, DOI: 10.1080/13825580600802893

To link to this article: https://doi.org/10.1080/13825580600802893

曲 Published online: 13 Apr 2007.

Submit your article to this journal $₫$

Џll Article views: 162

Q View related articles $\sqsubset$

4 Citing articles: 2 View citing articles 


\title{
Effects of Hormone Replacement Therapy and Aging on Cognition: Evidence for Executive Dysfunction
}

\author{
Domonick J. Wegesin And YaAkov Stern \\ G.H. Sergievsky Center, Columbia University, New York, New York
}

\begin{abstract}
The present study was designed to explore whether the frontal lobe hypothesis of cognitive aging may be extended to describe the cognitive effects associated with estrogen use in postmenopausal women. Postmenopausal estrogen-only users, estrogen + progesterone users, and non-users (60-80 years old), as well as young, regularly cycling women (18-30 years old) completed an item and source memory task. Since source memory is thought to rely more on executive processes than item memory, we hypothesized that aging and estrogen effects would be greater for source memory than for item memory. Neuropsychological tests explored whether the effects of aging and estrogen use were revealed on other tests of frontal lobe function. Results from the experimental task revealed greater aging and estrogen effects for source memory than for item memory, and neuropsychological results revealed aging and estrogen effects on a subset of tests of executive function. Women on estrogen + progesterone therapy did not outperform non-users, suggesting that the addition of progesterone to hormone therapy may mitigate the benefits induced by estrogen use alone. Overall, findings support the hypothesis that estrogen use may temper age-related cognitive decline by helping to maintain functions subserved by the frontal lobes.
\end{abstract}

The frontal lobe hypothesis of cognitive aging suggests that age-related cognitive decline reflects changes in executive processes subserved by the frontal lobes (Albert \& Kaplan, 1980; Dempster, 1992; West, 1996; Craik \& Jennings, 1992; Moscovitch \& Winocur, 1992; Stuss et al., 1996). The present study was designed to explore whether the frontal lobe hypothesis of cognitive aging may be extended to describe the cognitive effects associated with estrogen use.

Address correspondence to: Dr. Domonick J. Wegesin, G.H. Sergievsky Center, $19^{\text {th }}$ Floor, 630 West $168^{\text {th }}$ Street, New York, NY 10032. E-mail: wegesin@sergievsky.cpmc.columbia.edu 
Animal studies have established the biological plausibility for an association between estrogen use and frontal lobe function. Estrogen treatment administered to gonadectomized adult female rats resulted in a $40 \%$ increase in Choline acetyltransferase (ChAT) activity in the frontal cortex (Luine, 1985). In the dorsolateral prefrontal cortex (DLPFC) of monkeys, ovariectomy decreases the density of choline acetyltransferase fibers, which is restored with estrogen replacement (Kritzer and Kohama, 1999). High affinity choline uptake has been found to drop significantly in the rat frontal cortex following ovariectomy but is moderated by estrogen replacement (Singh et al., 1994). Estrogen has also been linked to an increase in serotonin binding within the frontal cortex (Summer \& Fink, 1995). Furthermore, dopaminergic innervation to frontal cortex, which is reduced by ovariectomy, is restored with estrogen replacement (Kritzer \& Kohama, 1998).

In humans, postmortem studies of the brain show high concentrations of estradiol in the prefrontal cortex (Bixo et al., 1995), and brain imaging studies have revealed effects of estrogen within the frontal cortex on cognitive activation tasks (Berman et al., 1997; Resnick et al., 1998). Neuropsychological studies examining the effects of estrogen on cognition have yielded mixed results (for reviews, see Birge, 1997; LeBlanc et al., 2001; Rice et al., 1997; Yaffe et al., 1998). Postmenopausal estrogen has been associated with enhanced performance on executive tests thought to tap frontal lobe function, e.g., working memory (Keenan et al., 2001; Duff \& Hampson, 2000) and reasoning ability (Fedor-Freybergh, 1977; Sherwin, 1988; Schmidt et al., 1996; Jacobs et al., 1998). However, the most consistent finding in the estrogen literature has shown estrogen-related enhancements in recall of verbal material (Caldwell \& Watson, 1952; Sherwin, 1988; Kampen \& Sherwin, 1994; Phillips \& Sherwin, 1992; Robinson et al., 1994; Hackman and Galbraith, 1977; Jacobs et al., 1998). Verbal memory processes reflect activity in many different brain regions, e.g., left-lateralized language centers (Ullman, 2001), the hippocampal memory system within the medial temporal lobe (Smith \& Halgren, 1989), and bilateral frontal lobe regions (Stuss et al., 1995). The frontal lobes are thought to be involved in "working with memory" retrieved from the hippocampal system (Moscovitch \& Winocur, 1992). Frontal lobe processes may include the implementation of complex mnemonic strategies to aid encoding and retrieval, the evaluation of how retrieved material relates to the task at hand, or the placement of retrieved material into spatial and temporal contexts (Wheeler et al., 1995; Stuss et al., 1996).

Recent functional brain imaging studies have provided evidence that age-related memory impairment may be related to changes in frontal lobe function. In healthy young adults, the left prefrontal cortex is more involved than the right prefrontal cortex in the encoding of episodic information, whereas the right prefrontal cortex is more involved than the left prefrontal 
cortex in the retrieval of episodic information (Moscovitch, 1994; Nyberg et al., 1996). This asymmetry is reduced in older adults, who show diminished prefrontal activity during encoding (Cabeza et al., 1997) and more extensive (bilateral) prefrontal activity during retrieval (Cabeza et al., 1997; Madden et al., 1999; also see Backman et al., 1997). One recent study has reported that postmenopausal women show a sharpening of this frontal asymmetry associated with encoding and retrieval during the estrogen phase of a crossover trial compared to during the placebo phase (Shaywitz et al., 1999). Thus, while taking estrogen, their frontal activity resembled more closely the pattern reported in healthy young women.

If changes in executive processing underlie age- and estrogen-related memory impairment, then the effects of aging and estrogen on memory should be greatest on memory tasks that tax executive processes the most. Among the memory tests in the current study, tests of recognition can occur relatively automatically (Jacoby, 1991), and are thought to involve fewer executive processes than free recall (Wheeler et al., 1995). Identifying the source of retrieved information is an effortful (as opposed to automatic) mnemonic process (Kausler et al., 1988) and may involve more executive processes subserved by the frontal lobes than does item recognition and free recall (Squire, 1987). To identify a memory's source, item and contextual cues retrieved from memory are submitted to various reflective processes such as planning, monitoring of irrelevant or interfering information, strategic retrieval of additional supporting information, and reasoning (Johnson et al., 1993). For example, one might know that a news item they recalled was seen on a television program that aired last Friday. The recollection of this additional temporal information allows the inference, "I learned this on Friday. 20/20 is on Fridays; thus, I must have learned about this on 20/20." Similarly, retrieval cue specification involves the use of general knowledge retrieved from semantic memory to guide source judgments. For instance, in attempting to recall who among a group of partygoers gave you news about the upcoming election, you may reason that, "it was Steve, because he was the only person at the party who is really interested in politics." These self-initiated monitoring and reasoning processes reflect executive control processes that are thought to depend on frontal lobe function. Given the heavy executive demands inherent in retrieving a memory's source, it is not surprising that impairments in source memory are commonly reported among patients with frontal lobe lesions (Janowsky et al., 1989b; Shimamura, 1996; Johnson et al., 1997).

Of the memory deficits associated with aging, decline is greatest on tests of source memory (Spencer \& Raz, 1995). Older adults are impaired at retrieving the temporal context (Fabiani \& Friedman, 1997; Trott et al., 1999; Wegesin et al., 2000), spatial context (Parkin et al., 1995; Zelinski \& Light, 1988), and perceptual context (McIntyre \& Craik, 1987) of previously experienced events. Source deficits are more conspicuous in older adults with 
poor executive functioning (Glisky et al., 1995) and are thought to reflect difficulty with initiating executive processes for integrating item information with contextual information during encoding (Glisky et al., 2001).

We hypothesize that if age and estrogen use affect the management of mnemonic information via executive functions mediated by the frontal lobes, then aging effects should be revealed on memory tests that place the greatest demands on executive processes with negligible differences revealed on memory tests that do not tax executive function. Specifically, we anticipate the smallest effects on tests of simple item recognition, moderate effects on tests of free recall, and the largest effects on the test of source memory.

Another question remaining in the hormone replacement literature relates to how the addition of progestagens to estrogen therapy impacts cognitive performance. Currently, progestagens are added to most hormone replacement regimens to eliminate the risk of endometrium hyperplasia due to unopposed estrogen. However, animal studies have shown that progesterone mitigates the beneficial effects of estrogens in the brain, such as neurite outgrowth (Woolley \& McEwen, 1993) and arterial circulation (Sarrel, 1990). The few human studies available are mixed, with the majority of studies demonstrating that progesterone counters the cognitive benefits associated with estrogen use alone (Sherwin, 1991; Janowsky et al., 1999; Ohkura et al., 1995; Rice et al., 2000), though at least two studies have failed to show this negative effect (Hogervorst et al., 1999; Maki et al., 2001). The current experiment contributes to resolving this question by comparing women treated with the combination of estrogen + progesterone to women taking estrogen alone. If progesterone attenuates the beneficial effects of estrogen, then we hypothesize that estrogen users will outperform estrogen + progesterone users on cognitive tests that are shown to be sensitive to estrogen use.

\section{MATERIAL AND METHODS}

\section{Participants}

Sixteen young (18-28) and 48 postmenopausal women (60-80) recruited by community flyers, newspaper advertisements, and word of mouth participated in the study. Postmenopausal participants were divided into three groups. "Estrogen users" were current users of estrogen only. "Est + Prog users" were current users of a combination of estrogen and progesterone. "Non-users" were women who were not currently taking and had never taken estrogen or progesterone. All participants were paid for their time. The institutional review boards of Columbia University and the New York State Psychiatric Institute approved the project, and all participants provided written informed consent.

Demographic profiles of the four groups are included in Table 1. Young women reported being of a lower socio-economic status (SES) than the 


\begin{tabular}{|c|c|c|c|c|c|c|c|c|}
\hline & \multicolumn{2}{|c|}{$\begin{array}{l}\text { Young } \\
\mathrm{N}=16\end{array}$} & \multicolumn{2}{|c|}{$\begin{array}{c}\text { Estrogen } \\
\mathrm{N}=15\end{array}$} & \multicolumn{2}{|c|}{$\begin{array}{c}\text { Est }+ \text { Prog } \\
N=16\end{array}$} & \multicolumn{2}{|c|}{$\begin{array}{c}\text { Non-Users } \\
\mathrm{N}=16\end{array}$} \\
\hline & $M$ & $S D$ & $M$ & $S D$ & $M$ & $S D$ & $M$ & $S D$ \\
\hline Age (years) & 21.50 & 2.71 & 68.69 & 6.05 & 67.63 & 5.10 & 70.94 & 5.04 \\
\hline Education (years) & 15.56 & 1.63 & 17.56 & 1.82 & 16.81 & 2.40 & 15.59 & 2.18 \\
\hline SES & 58.56 & 15.91 & 31.63 & 16.65 & 40.31 & 21.32 & 43.63 & 16.65 \\
\hline Modified MMSE & 55.31 & 1.62 & 54.94 & 1.91 & 54.56 & 1.90 & 54.31 & 2.09 \\
\hline Depression (short-care) & - & - & 2.13 & 1.45 & 2.47 & 1.64 & 2.56 & 2.03 \\
\hline Dementia (short-care) & - & - & 0.69 & 0.70 & 0.33 & 0.62 & 0.75 & 1.00 \\
\hline ADL (short-care) & - & - & 1.19 & 1.38 & 1.07 & 1.62 & 1.75 & 2.74 \\
\hline
\end{tabular}

older women $[\mathrm{F}(3,62)=6.8, p<.01]$ on a two-factor measure (occupation and education) of SES (Hollingshead \& Redlich, 1958). This is attributable to their occupational status as "student" and may not accurately reflect their true SES. Young women were also more ethnically diverse than the older groups $\left[\chi^{2}(9)=31.2, p<.001\right]$. Estrogen users completed more years of education $[\mathrm{F}(3,62)=3.8, p<.05]$ than young women $(p<.05)$ and non-users $(p<.05)$.

\section{Study Procedures}

Participants completed an initial telephone screening, followed by a more detailed screening in the lab. A semi-structured interview (Gurland et al., 1984) was administered to older participants to ensure that they were free from depression and dementia, and that they were not limited in the activities of daily living (see Table 1). Neuropsychological testing directly followed the lab screening for the young participants, but was scheduled for a subsequent visit for the old participants, due to the length of the semi-structured interview. Experimental testing and blood work took place on a separate visit for both young and old participants, such that the study involved two visits for young participants and three visits for old participants. For young women, the experimental testing (visit 2) was scheduled to correspond with the pre ovulatory phase of the menstrual cycle, when estrogen levels should be high and progesterone levels relatively low. Due to scheduling limitations, the menstrual cycle phase was not controlled for the first day of study participation when screening and neuropsychological tests were administered.

\section{Screening}

In an initial telephone screening, participants reported themselves to be native English speakers, in good physical health, and free from medications known to affect the central nervous system. The young women completed a 
menstrual cycle questionnaire (Schechter et al., 1989). Women included in the study reported a history of regular menstrual cycles without any skipped cycles or intra-cycle bleeding and reported no use of any hormone medications (e.g., birth control pills) in the last 12 months. There were no differences between the groups on a test of general cognitive status, the Modified Mini-Mental Status Exam (Mayeux et al., 1981).

\section{Blood Assays}

To confirm compliance to hormone therapy in the hormone users, blood samples were collected and Estradiol, E-1 Sulfate, and Follicle Stimulating Hormone (FSH) were measured in serum by a commercial solid-phase, chemiluminescent immunoassay (Diagnostic Systems Labs, Inc., Webster, TX). The polyclonal antibodies used are highly specific with low cross-reactivity to other steroids or hormones. To help confirm menstrual phase, progesterone was measured in the young women. An assay for the type of the synthetic progesterone used in the Est + Prog group was not available.

Serum assays were not available for five participants (one Estrogenuser, three Est + Prog users, one young woman) due to either the inability to draw blood at testing (two participants) or technical difficulties in the lab (three blood samples). Assay results shown in Table 2 confirmed that estrogen-users and Est + Prog users had higher circulating levels of estradiol [F $(2,41)=10.2, p<.001]$ and E1-Sulfate $[\mathrm{F}(2,41)=7.7, p<.01]$ than nonusers and that the two hormone-using groups did not differ in their estrogen levels. As anticipated, non-users showed higher levels of follicle-stimulating hormone than the two hormone-using groups $[\mathrm{F}(2,41)=8.9, p<.001]$. The results suggest coherence to the self-reported hormone therapies. Young women had higher levels of estradiol than all three groups of older women.

TABLE 2. Means and Standard Deviations for Hormonal Assays, Hormone Replacement Histories, and Menopausal Data

\begin{tabular}{|c|c|c|c|c|c|c|c|c|}
\hline & \multicolumn{2}{|c|}{$\begin{array}{l}\text { Young } \\
\mathrm{N}=15\end{array}$} & \multicolumn{2}{|c|}{$\begin{array}{c}\text { Estrogen } \\
\mathrm{N}=14\end{array}$} & \multicolumn{2}{|c|}{$\begin{array}{c}\text { Est }+ \text { Prog } \\
\mathrm{N}=13\end{array}$} & \multicolumn{2}{|c|}{$\begin{array}{c}\text { Non-Users } \\
\mathrm{N}=16\end{array}$} \\
\hline & $M$ & $S D$ & $M$ & $S D$ & $M$ & $S D$ & $M$ & $S D$ \\
\hline Estradiol (pg/ml) & 71.2 & 55.6 & 45.4 & 31.8 & 45.0 & 29.2 & 16.1 & 33.2 \\
\hline Estrone (ng/ml) & 7.9 & 1.4 & 10.6 & 11.8 & 8.0 & 5.7 & 2.0 & 1.7 \\
\hline Progesterone(ng/ml) & 2.0 & 3.8 & - & - & - & - & - & - \\
\hline FSH $(\mathrm{mIU} / \mathrm{ml})$ & 4.8 & 3.5 & 49.5 & 24.0 & 35.6 & 27.5 & 74.2 & 16.8 \\
\hline Age at menopause & - & - & 47.9 & 3.6 & 49.6 & 3.9 & 49.1 & 3.9 \\
\hline Years of hormone therapy & - & - & 11.5 & 10.9 & 8.0 & 5.0 & - & - \\
\hline Number of pregnancies & 0.3 & 0.6 & 1.9 & 1.7 & 2.3 & 1.4 & 2.6 & 2.1 \\
\hline Number never pregnant & 15.0 & & 7.0 & & 7.0 & & 4.0 & \\
\hline
\end{tabular}


In addition, progesterone levels in the young women were consistent with levels typical of the preovulatory phase of the cycle, suggesting that the timing of the experimental task based on the menstrual cycle questionnaire was accurate. Table 2 includes data on age at menopause and length of hormone treatment. No group effects were revealed on these variables.

\section{Experimental Testing}

\section{Item/Source Recognition Memory Test}

The design of the study was based on the paradigm originally published by McKoon and Ratcliff (1979), modified by Howard et al. (1986) and revised for Event-related potential (ERP) recording by Trott et al. (1999). A subset of the behavioral results for the young women and nonusers has been published in a study dealing with the ERP data resulting from this task (Wegesin et al., 2002). The item/source recognition memory test included a total of 16 study-test blocks. During the study phase, participants studied two separate lists of sentences of the following type-Noun 1 - VerbNoun 2 (e.g., "The chef created a spread"). Each list contained four sentences, for a total of eight nouns per list. Participants were instructed to memorize the two nouns, as well as the list in which they occurred, for a subsequent memory test. To enhance elaborative encoding, participants were asked to make subjective judgments of the study sentences, indicating whether or not they liked the sentence. No group differences were revealed for these subjective judgments. All groups reported "liking" approximately $68 \%$ of the sentences. To enhance encoding, they were given unlimited time to study the sentences, and their "like it/don't like it" judgments prompted the display of the next sentence. Analyses of study timing failed to reveal any group differences; participants studied each sentence for approximately 6.3 second on average. In order to aid encoding of the study nouns, each sentence appeared twice within the list in randomized order. At the end of List 1 , a line drawing depicting a nonverbal cartoon appeared, which was used to demarcate the two lists.

Immediately following the final "like it/don't like it" judgment of the second study list, a prompt reading "Test" was presented for $5000 \mathrm{~ms}$ to prepare participants for the onset of the test phase. During the test phase, nouns were presented sequentially in pairs, each with a $300 \mathrm{~ms}$ duration separated by a $2000 \mathrm{~ms}$ ISI. A total of 256 sentences was divided into two sets, balanced for word frequency and length, and served as either study or foil sentences (counterbalanced across participants). Participants made speeded and accurate old/new recognition judgments to each of the two nouns (responding hands counterbalanced across participants). If either noun was judged old, that noun was represented and a nonspeeded source (i.e., list) judgment was made. Source judgments were cued by prompts that read "List 1" and "List 2" presented on the left and right lower corners of the computer screen (counterbalanced across participants). 
Dependent variables from the experimental task included the number of correctly identified old words (hits), the number of false alarms, and a measure of item discrimination that incorporates both hits and false alarms. Response bias indexes an individual's tendencies to respond "old" or "new" to test items. A conservative bias has been reported previously in older adults, reflecting less likelihood to respond "old" (Poon \& Fozard, 1980). Measures of item discrimination $\left(\mathrm{d}_{\mathrm{L}}\right)$ and response bias $\left(\mathrm{c}_{\mathrm{L}}\right)$ were based on logistic distributions in a signal detection model (Snodgrass \& Corwin, 1988). Reaction times to old and new items were also compared. Source memory scores reflect the percent of correctly identified old words that were subsequently attributed to the correct list.

\section{Neuropsychological Testing}

Neuropsychological tests provided measures of executive processes, including problem-solving, reasoning, set shifting, attention, and working memory. Tests of memory included measures of verbal and visual immediate and delayed recall, as well as measures of verbal recognition.

\section{Executive Function}

The complete version of the Wisconsin Card Sort Test (WCST; Heaton, 1981) assesses problem-solving or reasoning, attention, and the ability to shift cognitive strategies, processes that are thought to rely heavily upon the frontal lobes (Milner, 1963; Nagahama et al., 1997). Dependent measures from the task include failure to maintain set, number of errors, and number of perseverative errors. Two tests of working memory and attention were included. First, the Letter-Number Sequencing Subtest of the WAIS-III requires participants to sort a mixed series of letters and numbers maintained in memory and repeat them back in sorted order, giving the numbers first in ascending order and then the letters in alphabetical order. Second, the digit span backwards portion of the digit span test requires participants to hold arrays of numbers in mind, while repeating them back in the reverse order to which they were originally heard. Scores reflect the total number of correctly repeated items. Both tasks require manipulation of information held in short-term memory, and are assumed to recruit processes dependent upon the prefrontal cortex (Canavan et al., 1989; Tsukiura et al., 2001). Two tests of verbal fluency were administered. Verbal fluency involves several mental operations including attention, word retrieval, strategy implementation, setshifting, and abstract reasoning, and has been shown to activate left dorsolateral and ventrolateral prefrontal cortex (Schloesser et al., 1998). The Controlled Oral Word Association Test or CFL test (Benton \& Hamsher, 1978), a test of phonemic fluency, requires participants to say, as quickly as they can, all of the words that they can think of (excluding proper names) beginning with the letters "C," "F," and "L," each administered for 1 minute. 
Category fluency requires participants to say, as quickly as they can, all of the words they can think of that belong to a named category (animals, foods, clothing) each administered for one minute.

\section{Immediate Verbal Recall}

In part 1 of the Logical Memory Subtest of the Wechsler Memory Scales-III (WMS-III; Wechsler, 1997), participants attempt to recall as many details of a short story immediately after it is read to them. Five of the women completed the WMS-R (Wechsler, 1981) version of the Logical Memory Subtest participating in a related study. To avoid practice effects from repeated administration of the Logical Memory subtest, data from the WMS-R test was used for these five participants. As such, story A was used to calculate story immediate recall, since this story is identical in the WMS$\mathrm{R}$ and WMS-III versions of the test. Scores for immediate paragraph memory represent the number of items recalled from story A.

In the Selective Reminding Test (SRT; Bushke \& Fuld, 1974) participants are given six trials to learn a list of 12 unrelated words. After each recall attempt, a selective reminding procedure is used wherein participants are reminded only of those words that they had not successfully recalled. They are then asked to recall the entire list of 12 words. Measures of SRT sensitive to aging (Larrabee et al., 1988) and estrogen-use (Jacobs et al., 1998) were selected and include long-term storage, which reflects the number of words recalled on two or more consecutive trials without intervening reminding, and consistent long-term retrieval, which reflects words consistently recalled without error for the remainder of the test trials.

\section{Delayed Verbal Recall}

For part 2 of the Logical Memory Subtest of the WMS-III (Wechsler, 1997) (or for five participants WMS-R (Wechsler, 1981)), participants are asked to recall the stories they heard in Logical Memory I after a 30-minute delay. As with immediate recall, only the first story, which is identical in both version of the Logical Memory test, was used. Although the story and the retention delay are identical in both versions of the test, it should be noted that the WMS-III version includes more verbal interference compared to the WMS-R version, since the second story of the test (not used here for analysis) is read twice in the WMS-III, as opposed to being read only once in the WMS-R. The scores of the five participants who completed the WMS-R version of the Logical Memory Subtest did not differ from those who completed the WMS-III version. For the Selective Reminding Test, free delayed recall of the 12-item list is assessed after a 15-minute delay. Since both of these delay measures are biased, based on the amount of information originally encoded, savings measures were calculated. Total savings reflects the percentage of originally encoded information that is retained and recalled after the imposed delay. 


\section{Verbal Recognition}

Following the delayed story recall of the Logical Memory test, participants are asked a series of 30 yes/no questions about the story. Scores reflect the total number of correct responses. Recognition was also assessed in the Selective Reminding Test. For any of the 12 items not spontaneously recalled on delayed recall, participants are given a four-choice recognition test in which the target item is presented with three foil items. Total recognition score reflects items freely recalled, plus those correctly recognized from the four-choice arrays.

\section{Immediate and Delayed Visual Recall}

In part 1 of the Visual Reproduction Subtest of the Wechsler Memory Scales-III, WMS-III (Wechsler, 1997), participants study and then attempt to draw a series of figures, including as many details as possible. For part 2 of the Visual Reproduction Subtest, women attempt to draw the figures again after a 30-minute delay. Scores for the immediate test reflect the number of details accurately included in the participants' drawing. Scores for the delayed test reflect the percentage of originally encoded information that is retained and recalled after the imposed delay.

\section{Data Analysis}

Two sets of analyses were conducted. The first set examined the effects of aging and estrogen use by comparing the data from estrogen users, nonusers, and young women in an analysis of covariance (ANCOVA). Education was covaried in these analyses, since estrogen users completed more years of education than the young women and non-users. Bonferroni-corrected, posthoc tests were conducted on the education-adjusted means. One estrogen user, who scored out of range on several neuropsychological measures and performed below chance level on the experimental paradigm, was dropped from the analyses. Aging effects were examined in two ways. First, the young women were compared to postmenopausal non-users in order to evaluate our data against the extant aging literature, the vast majority of which did not control for hormone use. Second, the young women were compared to the postmenopausal estrogen users in an attempt to examine the effects of aging while providing some control over the effects of estrogen status, since the estrogen users most resembled the young women in circulating estrogen levels. Estrogenic effects were noted by significant differences revealed between the estrogen users and the non-users from the Bonferroni-corrected, post-hoc tests.

The second set of analyses was designed to assess the effect of opposing estrogen with progesterone on the neuropsychological and experimental measures. For these analyses, estrogen users and est + prog users were compared. No covariate was applied to these analyses, as the groups did not differ on any demographic variables. 
Effect sizes were calculated for aging effects (young vs. non-users and young vs. estrogen users), estrogen effects (estrogen users vs. non-users), and progesterone effects (estrogen users vs. est + prog users). Cohen (1988) defined effect sizes as small $(0.20)$, medium $(0.50)$, and large $(0.80)$.

\section{RESULTS}

\section{Analysis 1: Effects of Estrogen Use and Aging \\ Experimental Results}

\section{Item and Source Recognition}

Behavioral results for all four groups are shown in Table 3. Comparisons for Analysis 1 of the estrogen users, non-users, and young women are reported in Table 4, and effect size data are available in Table 5. The item discrimination index revealed an aging effect whereby young women discriminated old and new words more accurately than both non-users $(p<.001)$ and estrogen users $(p<.01)$. Estrogen users showed a modest trend towards discriminating old and new words better than the non-users $(p<.10)$. The components of the discrimination index revealed an aging effect for the false alarm rate and hit rate. For false alarms, young women committed fewer false alarms than both non-users $(p<.001)$ and estrogen users $(p<.05)$. For the hit rate, young women correctly identified more old words than non-users $(p<.01)$ but not more than the estrogen users. The false alarm rate did not differ between estrogen users and non-users, though estrogen users tended to identify old words more accurately than non-users $(p<.10)$. Reaction time measures for the item recognition task (shown in Table 3 ) revealed effects of aging; young women were significantly faster than both non-users $(p<.01)$ and estrogen users $(p<$ .05 ) in identifying old words, as well as new words (non-users, $p<.01$; estrogen users, $p<.01$ ). Reaction time measures for estrogen users and non-users did not differ significantly. The measure of response bias revealed that all groups were similarly conservative in their judgments. Scores for source recognition revealed both aging and estrogen effects. Young women correctly identified the list of old items better than both the non-users $(p<.001)$ and the estrogen users $(p<.01)$. Source recognition scores of the estrogen users were higher than scores of the non-users $(p<.01)$.

\section{Neuropsychological Results}

\section{Executive function}

As shown in table 3, performance on the WCST revealed both aging and estrogen effects. Non-users committed more errors on the WCST than did the estrogen users $(p<.01)$ and young women $(p<.01)$. In addition, non-users committed more perseverative errors than did estrogen users 


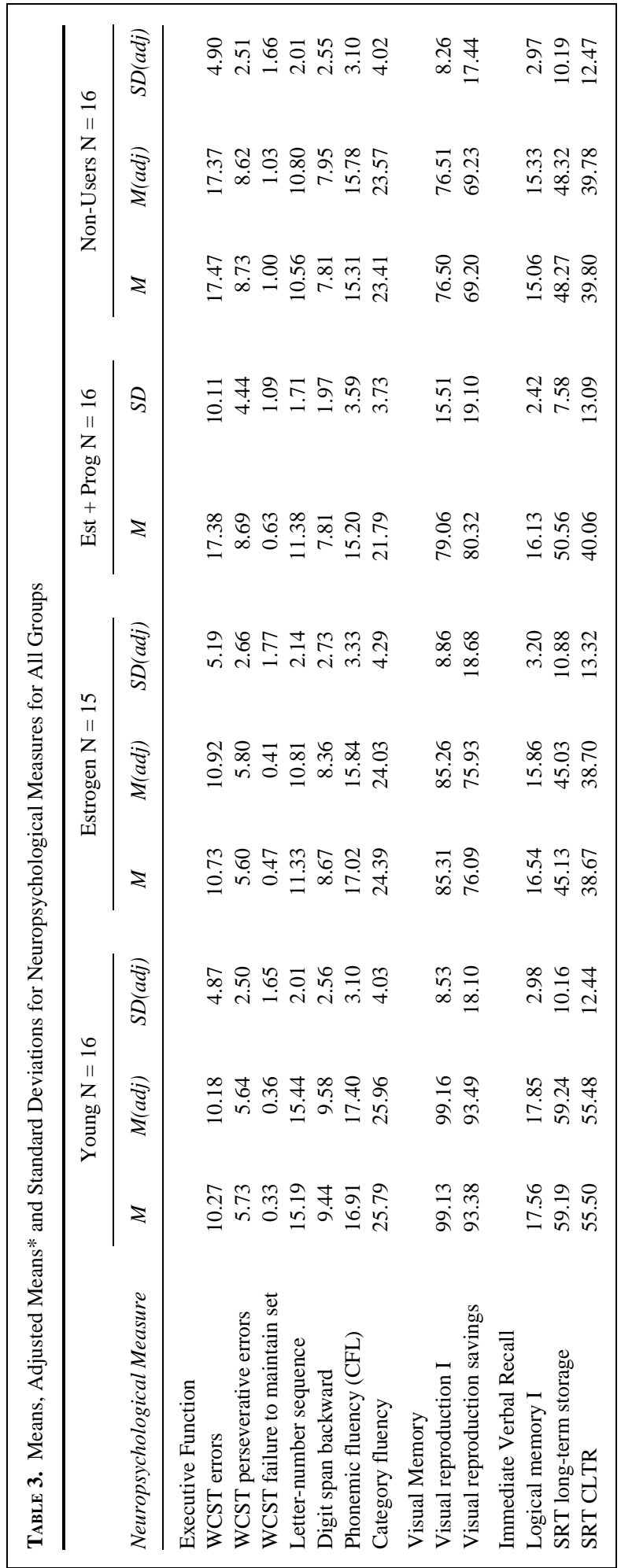


గ心

$\infty \underset{0}{\infty}$ त

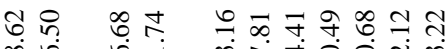

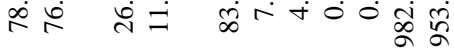

ते

mํำ

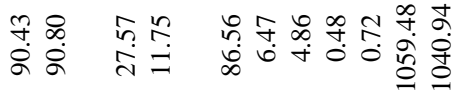

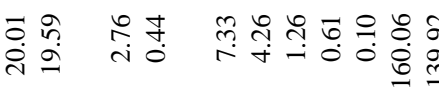

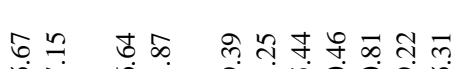

舟交

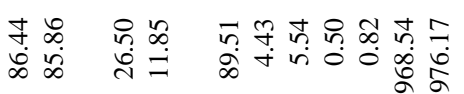

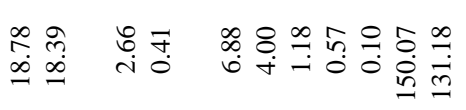

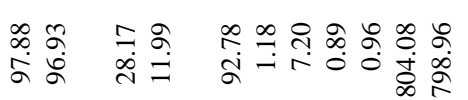

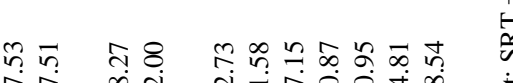

नूँ

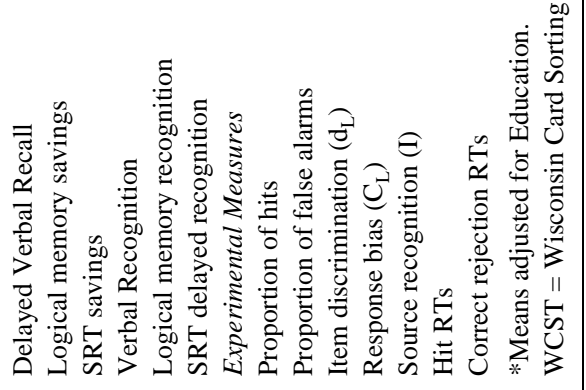




\begin{tabular}{|c|c|c|c|c|}
\hline \multirow[b]{2}{*}{ Neuropsychological Measures } & \multicolumn{2}{|c|}{$\begin{array}{l}\text { Young vs. Estrogen } \\
\text { vs. Non-Users }\end{array}$} & \multicolumn{2}{|c|}{$\begin{array}{c}\text { Estrogen vs. } \\
\text { Estrogen + Prog }\end{array}$} \\
\hline & $F$ & $p$ & $F$ & $p$ \\
\hline \multicolumn{5}{|l|}{ Executive Function } \\
\hline WCST errors & 7.15 & 0.00 & 5.63 & 0.03 \\
\hline WCST perseverative errors & 5.42 & 0.00 & 6.28 & 0.02 \\
\hline WCST fail to maintain set & 0.52 & 0.67 & 0.19 & 0.67 \\
\hline Letter-number sequence & 18.73 & 0.00 & 0.00 & 0.95 \\
\hline Digit span backward & 1.52 & 0.22 & 1.28 & 0.27 \\
\hline Phonemic fluency (CFL) & 4.27 & 0.01 & 2.54 & 0.12 \\
\hline Category fluency & 1.21 & 0.32 & 3.55 & 0.07 \\
\hline \multicolumn{5}{|l|}{ Visual Memory } \\
\hline Visual reproduction I & 18.67 & 0.00 & 1.67 & 0.21 \\
\hline Visual reproduction savings & 4.86 & 0.00 & 0.27 & 0.61 \\
\hline \multicolumn{5}{|l|}{ Immediate Verbal Recall } \\
\hline Logical memory I & 3.19 & 0.05 & 0.22 & 0.64 \\
\hline SRT long-term storage & 5.74 & 0.00 & 2.10 & 0.16 \\
\hline SRT consistent long-term retrieval & 6.24 & 0.00 & 0.10 & 0.78 \\
\hline \multicolumn{5}{|l|}{ Delayed Verbal Recall } \\
\hline Logical memory savings (Part A) & 2.98 & 0.04 & 0.44 & 0.51 \\
\hline SRT savings & 3.59 & 0.02 & 1.43 & 0.24 \\
\hline \multicolumn{5}{|l|}{ Verbal Recognition } \\
\hline Logical memory recognition & 2.07 & 0.12 & 0.07 & 0.80 \\
\hline SRT delayed recognition & 1.10 & 0.36 & 0.36 & 0.56 \\
\hline \multicolumn{5}{|l|}{ Experimental Measures } \\
\hline Proportion of hits & 5.66 & 0.00 & 1.75 & 0.20 \\
\hline Proportion of false alarms & 8.83 & 0.00 & 0.10 & 0.33 \\
\hline Item discrimination $\left(\mathrm{d}_{\mathrm{L}}\right)$ & 15.93 & 0.00 & 4.68 & 0.04 \\
\hline Response bias $\left(\mathrm{C}_{\mathrm{L}}\right)$ & 1.82 & 0.16 & 0.00 & 0.95 \\
\hline Source recognition (I) & 23.72 & 0.00 & 6.51 & 0.02 \\
\hline Hit RTs & 5.53 & 0.00 & 4.26 & 0.05 \\
\hline Correct rejection RTs & 5.95 & 0.00 & 2.53 & 0.12 \\
\hline
\end{tabular}

$(p<.05)$ and young women $(p<.05)$. No differences were observed for either error measure between estrogen users and young women, and no differences were revealed on the WCST measure of maintaining a cognitive set among any of the three groups. The Letter-Number Sequence test showed highly significant effects of aging, whereby young women outscored non-users $(p<.001)$ and estrogen users $(p<.001)$. No effects of estrogen use were observed. Scores on the Digit Span Backward subtest and Category Fluency Test did not differ significantly among the three groups. Scores on the Phonemic Fluency Test did produce a main group 
TABLE 5. Effect Sizes for Comparisons of Interest for Neuropsychological and Experimental Measures

\begin{tabular}{|c|c|c|c|c|}
\hline & $\begin{array}{c}\text { Young vs. } \\
\text { Estrogen } \\
d\end{array}$ & $\begin{array}{c}\text { Young vs. } \\
\text { Non-Users } \\
d\end{array}$ & $\begin{array}{c}\text { Estrogen vs. } \\
\text { Non-Users } \\
d\end{array}$ & $\begin{array}{c}\text { Estrogen vs. } \\
\text { Est }+ \text { Prog } \\
d\end{array}$ \\
\hline \multicolumn{5}{|l|}{ Effect Size } \\
\hline \multicolumn{5}{|l|}{ Executive Function } \\
\hline WSCT errors & 0.15 & 1.47 & 1.28 & 0.84 \\
\hline WCST perseverative errors & 0.06 & 1.19 & 1.09 & 0.81 \\
\hline WCST failure to maintain set & 0.03 & 0.40 & 0.36 & 0.15 \\
\hline Letter-number sequence & 2.23 & 2.31 & 0.00 & 0.30 \\
\hline Digit span backward & 0.46 & 0.64 & 0.15 & 0.23 \\
\hline Phonemic fluency (CFL) & 0.49 & 0.52 & 0.02 & 0.18 \\
\hline Category fluency & 0.46 & 0.59 & 0.11 & 0.56 \\
\hline \multicolumn{5}{|l|}{ Visual Memory } \\
\hline Visual reproduction I & 1.60 & 2.70 & 1.02 & 0.51 \\
\hline Visual reproduction savings & 0.95 & 1.37 & 0.37 & 0.23 \\
\hline \multicolumn{5}{|l|}{ Immediate Verbal Recall } \\
\hline Logical memory I & 0.64 & 0.84 & 0.17 & 0.09 \\
\hline SRT long-term storage & 1.35 & 1.07 & 0.31 & 0.60 \\
\hline SRT consistent long-term retrieval & 1.30 & 1.26 & 0.08 & 0.10 \\
\hline \multicolumn{5}{|l|}{ Delayed Verbal Recall } \\
\hline Logical memory savings (Part A) & 0.63 & 1.03 & 0.36 & 0.29 \\
\hline SRT savings & 0.51 & 1.11 & 0.56 & 0.24 \\
\hline \multicolumn{5}{|l|}{ Verbal Recognition } \\
\hline Logical memory recognition & 0.57 & 0.57 & 0.02 & 0.39 \\
\hline SRT delayed recognition & 0.29 & 0.61 & 0.29 & 0.23 \\
\hline \multicolumn{5}{|l|}{ Experimental Measures } \\
\hline Proportion of hits & 0.48 & 1.40 & 0.88 & 0.41 \\
\hline Proportion of false alarms & 0.98 & 1.66 & 0.62 & 0.21 \\
\hline Item discrimination $\left(\mathrm{d}_{\mathrm{L}}\right)$ & 1.45 & 2.37 & 0.84 & 0.55 \\
\hline Response bias $\left(\mathrm{C}_{\mathrm{L}}\right)$ & 0.73 & 0.70 & 0.06 & 0.04 \\
\hline Source recognition (I) & 1.48 & 2.91 & 1.33 & 0.81 \\
\hline Hit RTs & 0.94 & 1.19 & 0.21 & 0.80 \\
\hline Correct rejection RTs & 1.30 & 1.18 & 0.16 & 0.54 \\
\hline
\end{tabular}

effect, though Bonferroni-corrected, post-hoc tests failed to reveal significant group differences.

\section{Immediate Verbal Recall}

Measures of immediate verbal recall revealed significant group effects. Post-hoc tests for paragraph recall (Logical Memory I) revealed that young women tended to remember more material than non-users $(p=.05)$. Paragraph recall scores for estrogen users were intermediate to those of the young women and non-users and did not differ significantly from the scores 
of either group. Post-hoc tests for list recall revealed significant aging effects. Young women had higher SRT Long Term Storage scores than both non-users $(p<.05)$ and estrogen users $(p<.01)$, as well as higher SRT Consistent Long Term Retrieval scores than both non-users $(p<.01)$ and estrogen users $(p<.01)$. The SRT list recall measures did not differ between estrogen users and non-users.

Delayed Verbal Recall

Aging effects on measures of delayed verbal recall showed that the percentage of saved material from the paragraph in the Logical Memory subtest was higher in young women than in non-users $(p<.05)$. Similarly, the percentage of saved material from the list of words in the SRT was greater in young women than in the non-users $(p<.01)$. Savings scores for estrogen users were intermediate to those of the young women and non-users and did not differ significantly from the scores of either group.

\section{Verbal Recognition}

No differences were revealed between any of the groups on recognition measures from the Logical Memory subtest or from the SRT.

\section{Visual Immediate and Delayed Recall}

The Visual Reproduction I subtest revealed both effects of aging and estrogen use. At the immediate delay, young women reproduced more figural information than the non-users $(p<.001)$ and estrogen users $(p<.01)$. In addition, estrogen users reproduced more figural information than the non-users $(p<.05)$. However, recall for the material after a 30-minute delay revealed only aging effects, as the percentage of saved material was higher in young women compared to both non-users $(p<.01)$ and estrogen users $(p<.05)$. Estrogen users and non-users recalled an equivalent percentage of the initially encoded information at the 30-minute delay.

\section{Analysis 2: Effects of Progesterone}

\section{Experimental Results}

\section{Item and Source Recognition}

Estrogen users discriminated old and new words better than est + prog users and were faster than est + prog users on the task (see Tables 3, 4, and $5)$. Estrogen users also showed better source recognition performance than the est + prog users.

\section{Neuropsychological Results}

Generally, neuropsychological scores of the est + prog users did not differ significantly from the estrogen users (see Tables 3, 4, and 5). 
Measures from the WCST were the exception; est + prog users committed more total errors and more perseverative errors on the WCST than did estrogen users.

\section{DISCUSSION}

The present study tested the hypothesis that the frontal lobes mediate aspects of age-related cognitive decline and that estrogen use may help temper agerelated cognitive decline by helping to maintain executive functions subserved by the frontal lobes. Two sets of evidence supported this hypothesis. First, aging and estrogen effects were greatest for tests of source memory, the memory measure that presumably relies most on executive processes and frontal lobe function. Second, aging and estrogen effects were revealed on neuropsychological tests of executive function, e.g., measures from the WCST. However, null findings on other tests of executive function failed to support the frontal lobe hypothesis of cognitive aging.

To our knowledge, this is the first study to examine source memory in postmenopausal estrogen users. Results revealed a robust estrogenic effect on source memory compared to a nonsignificant estrogenic effect on item memory. The disproportionate deficit in source memory compared to item memory is consistent with the pattern revealed in our aging results and in the aging literature (for a review, see Spencer \& Raz, 1995). Note that the size of the age effects reported in the current study was elevated due in part to the consistently high performance and reduced variability of the young subjects. Patients with frontal lobe damage are impaired in making source memory judgments (Butters et al., 1994; Mangels, 1997; Milner et al., 1991; Shimamura, 1996), as are nonhuman primates with discrete mid-dorsal frontal lesions (Petrides, 1991). Brain imaging studies in healthy controls have also demonstrated frontal lobe involvement in source memory tasks (Rugg et al., 1999; Nolde et al., 1998; Henson et al., 2000; Cabeza et al., 1997). Therefore, large aging and estrogenic effects for source memory provide the strongest support for the hypothesis that aging and estrogenic effects are mediated by frontal lobe processes. However, this finding is not meant to imply that source memory is subserved exclusively by the frontal lobes.

An aging effect (and a trend towards an estrogen effect) was also revealed on the experimental measure of item discrimination. By contrast, measures of item recognition from the neuropsychological battery showed no group effects. Since simple item recognition can be performed relatively automatically (Jacoby, 1991), aging and estrogen effects were unanticipated. The discrepancy between experimental and neuropsychological measures may be due to the task demands involved in the experimental test. Specifically, participants were required to make speeded item judgments and, for items judged old, nonspeeded source judgments. Older participants reported 
difficulty in rapidly switching back and forth between these two judgment types. Task switching is a metacognitive regulatory process that declines with aging and is thought to rely upon frontal lobe function (McDowd et al., 2000; West, 1996; Fernandez-Duque et al., 2000). Further, making speeded item judgments in the experimental task is more demanding than making nonspeeded judgments in the neuropsychological tests. Speeded item recognition tests have been shown to activate a fronto-parietal network (Zysset et al., 2001). Thus, a portion of the variation in performance on the experimental item recognition test likely involved variation in executive capacity and frontal lobe function. In contrast, the "yes/no" recognition and multiplechoice recognition tests from the neuropsychological battery did not require such regulatory processes. Intact simple item recognition in the neuropsychological measures supports the hypothesis that the hippocampal memory system remains relatively intact in normal aging (West, 1996).

The most consistent finding in the estrogen literature reflects a benefit of estrogen use on the recall of verbal information (Caldwell \& Watson, 1952; Sherwin, 1988; Kampen \& Sherwin, 1994; Phillips \& Sherwin, 1992; Robinson et al., 1994; Hackman \& Galbraith, 1977; Jacobs et al., 1998). The current study provided little support for such an association. Specifically, estrogen users did not outperform the non-users on any measure of immediate or delayed verbal recall from the neuropsychological battery. Instead, scores for estrogen users were intermediate to those of young women and non-users. Other studies have also failed to find effects of estrogen on verbal recall (Barret-Conner \& Kritz-Silverstein, 1993; Duff \& Hampson, 2000; Kampen \& Sherwin, 1994; Rice et al., 2000; Robinson et al., 1994). Most reports yielding significant effects are conducted with recently menopausal women, who are thus likely experiencing menopausal symptoms. Studies of asymptomatic women typically yield null results (for a review, see LeBlanc et al., 2001). Given that the women in the current study have been menopausal for an average of 22 years, and likely not experiencing significant menopausal symptoms, these data are congruent with the extant literature. Unfortunately, data on menopausal symptoms were not collected in this study, therefore precluding an examination of the relationship between menopausal symptoms and cognitive performance.

Aging effects were revealed on both immediate and delayed recall measures of paragraph and list memory. The frontal lobe hypothesis predicts greater aging effects on tests that place more demands on executive processes. For instance, tests of free recall require more self-initiated retrieval processes than do tests of recognition (Craik \& Lockhart, 1986). Accordingly, the aging effect size for recall was predicted to be greater than the aging effect size for recognition. Table 5 shows this prediction was supported in the current data. Further, executive demands are greater for encoding an unassociated list compared to encoding information that is somehow 
related, e.g., related semantically or related in the context of a meaningful sentence (Baddeley et al., 1987). Thus, aging effects should be greater for list recall compared to paragraph recall. Corresponding to this prediction, results revealed greater aging effects for SRT measures compared to logical memory measures. In fact, the difference between young women and nonusers for paragraph recall was only marginally significant $(p=.05)$. Altogether, the aging effects for recall and recognition support the hypothesis that memory deficits in older adults reflect executive deficits.

For visual memory, effects of estrogen use were not anticipated, as previous studies have generally failed to reveal differences between estrogen users and non-users (Barret-Conner \& Kritz-Silverstein, 1993; Carlson \& Sherwin, 1998; Polo-Kantola et al., 1998; Phillips \& Sherwin, 1992). Of note is the pattern whereby estrogenic effects are revealed on tests of immediate memory, but not on those of delayed memory. Baddeley has suggested that preserved immediate recall reflects the absence of impairment in the functioning of the central executive system (Baddeley, 2000). For example, some amnesic patients who show impaired memory after a delay show immediate memory scores in the normal range (Wilson \& Baddeley, 1988). Further, short-term visuospatial memory in healthy controls has been recently shown to be strongly related to executive function (Miyake et al., 2001), and brain imaging studies have revealed activation of frontal structures during visual memory encoding and retrieval (Angioi-Duprez et al., 2000). Accordingly, differences between estrogen users and non-users in immediate visual memory may be related to differences reported in executive processes that help supervise the memory process.

Frontal lobe involvement in age-related memory decline is based on the premise that elders mismanage retrieved memories due to impaired executive functions (Jacoby, 1994; Salthouse, 1990b). In support of this hypothesis, our data showed the largest age and estrogen effects on performance of the WCST. Specifically, non-users committed more errors overall, as well as more perseverative errors, than the young women and estrogen users. Results replicate previous studies showing effects of aging (Spreen \& Strauss, 1998) and estrogen use (Schmidt et al., 1996) on WCST measures. Further, given that the WCST relies on reasoning ability, the result supported findings indicating enhanced reasoning ability among estrogen users (Fedor-Freybergh, 1977; Sherwin, 1988; Schmidt et al., 1996; Jacobs et al., 1998).

Perseverative errors on the WCST are particularly indicative of dysfunction in the prefrontal cortex (Grafman et al., 1990; Janowsky et al., 1989a), specifically DLPFC (Taylor, 1979). Structural imaging has revealed that age-related reductions in the volume of DLPFC are associated with an increase in perseverative errors on the WCST (Raz et al., 1998). The magnitude of PET activation in DLPFC is reduced in older adults compared to 
younger adults during performance of a modified version of the WCST (Nagahama et al., 1997). The administration of Lupron, used to suppress gonadal steroids including estrogen, leads to an attenuation of PET activation within the DLPFC during the WCST. This activation is restored with the administration of exogenous estrogen (Berman et al., 1997). Together, these findings provide strong evidence associating age and estrogen use with changes in executive functions associated with DLPFC.

Aging effects were also revealed on a test of working memory, LetterNumber Sequencing. Decreases in working memory capacity are claimed to result in a broad range of age-related cognitive deficits (for a review, see Salthouse, 1990a). The prefrontal cortex has clearly been shown to underlie aspects of working memory in lesion studies in monkeys (Funahashi et al., 1993), in studies of humans with prefrontal damage (Verin et al., 1993; Ferreira et al., 1998; Gron, 1998), and in studies of human brain imaging (for a review, see D'Esposito et al., 2000). Given the clear involvement of prefrontal cortex in working memory, we anticipated that estrogen users would outperform non-users on the working memory test. However, results failed to reveal effects of estrogen, which is consistent with the majority of reports in the literature (Carlson \& Sherwin, 1998; Phillips \& Sherwin, 1992; Ditkoff et al., 1991; Shaywitz et al., 1999; Polo-Kantola et al., 1998; Barret-Conner \& Kritz-Silverstein, 1993; also see Sherwin, 1988; Carlson \& Sherwin, 1998; Duff \& Hampson, 2000). Most studies have used backward digit span to assess working memory. Null aging and estrogen effects on digit span may reflect the fact that span tests may not provide information on executive control (Stuss \& Levine, 2002) and may not depend on intact frontal lobe function (D'Esposito \& Postle, 1999). On a more complex digitreordering span test, Duff and Hampson (2000) reported estrogen effects. Therefore, tests that require more manipulation of the data held in working memory may be more sensitive to estrogen use. However, this possibility is not supported in the current data, as the most demanding working memory task (Letter-Number Sequencing Test), showed equivalent performance in estrogen users and non-users.

Overall, aging effects were greatest for tests that taxed specific executive functions, i.e., those involving metacognitive monitoring, reasoning, working memory, and extra-dimensional set-shifting. These same executive functions, except for working memory, appear to be preserved in older women using estrogen. We next examined whether a similar pattern of benefits on executive function was seen in women taking a combination of est + prog.

Opposing estrogen with progesterone appears to reverse some of the beneficial effects of taking estrogen alone. Est + prog users committed more overall errors, as well as more perseverative errors, on the WCST compared to estrogen users, reflecting impaired executive function. Est + prog users 
also performed worse on the item/source memory task. These same tasks showed the strongest effects of estrogen use; thus, the deleterious effects of progesterone on cognitive function were specific to tests that benefited from estrogen use. This finding supports other studies that reported detrimental effects of progesterone on cognitive abilities (Sherwin, 1991; Ohkura et al., 1995; Rice et al., 2000), though at least two studies have failed to find such negative effects (Hogervorst et al., 1999; Maki et al., 2001). Additional data consistent with the present findings show that progestagens can dampen mood (Sherwin, 1991) and are suspected to decrease activity of excitatory neurotransmitters (Backstrom et al., 1985). Certain metabolites of progesterone, such as allopregnanolone, are known to bind to $\mathrm{GABA}^{\mathrm{A}}$ receptors and produce sedative-like effects (Purdy et al., 1990). Basic neurobiological studies have also shown that most of the beneficial effects of estrogen on the brain, e.g., affecting neurotransmitter synthesis (McEwen et al., 1977), altering neuronal morphology (Woolley \& McEwen, 1993), and enhancing cerebral perfusion (Funk et al., 1991) are opposed by progesterone (Sarrel, 1990). Human studies including treatments of progesterone alone are needed to provide further insights into the impact of progesterone on cognitive function in postmenopausal women.

The present study is limited by its observational nature. Since women were not randomly assigned to a treatment group, the effects of hormone use are confounded with subject variables that may differentiate women who choose to use hormones after menopause from those who do not. Previous research has shown that hormone users tend to be healthier and better educated than nonhormone users (Egeland et al., 1991; Matthews et al., 1996). A critical control comparison in the present study is between the estrogen only and the est + prog groups. Since both groups had chosen to use hormones, differences between them on tests of executive function and source memory could not be attributed to subject factors related to self-selection for hormone use. Clinical trials represent the strongest design for assessing estrogen's impact on cognitive function. Unfortunately, trials currently available typically have relatively small numbers of participants, which may prohibit the detection of small effects of estrogen, or they are short in duration, which may prohibit the detection of estrogenic effects that develop over time. For example, Jacobs et al. (1998) reported cognitive differences between women taking estrogen for less than 1 year and women taking estrogen for more than 1 year. Large clinical trials that continue treatment over the course of at least 1 year are needed to help resolve the conflicting findings available to date.

Finally, it has been argued that the cognitive benefits associated with estrogen use are a by-product of changes in mood associated with estrogen use. Since direct measures of mood were not collected, we cannot discount this possibility. However, the three postmenopausal groups did not differ on measures of depression or activities of daily living, as assessed by the CARE. This 
suggests that the cognitive differences reported between estrogen users and non-users are not likely attributable to differences in mood or general health, consistent with what has been reported previously (e.g., Duka et al., 2000).

In conclusion, the pattern of behavioral and neuropsychological findings converge to provide evidence that impairment in executive functions in older adults may account for cognitive deficits associated with aging and that estrogen may attenuate these deficits by helping to preserve specific executive functions subserved by the frontal lobes. Results also suggest that opposing estrogen with progesterone may mitigate the cognitive benefits of taking estrogen alone.

\section{ACKNOWLEDGMENTS}

The authors gratefully acknowledge David Friedman and Nina Varughese for assistance on many aspects of the study implementation and for manuscript review, Charles L. Brown III for computer programming and technical assistance, Charlotte Trott for assistance in task development, Michel Ferin for processing the blood assays, and the volunteers for their time and cooperation. This study was supported in part by K01 AG00879-01 and R03 AG1639601 from National Institute of Aging (NIA).

Original manuscript received November 4, 2002

Revised manuscript accepted January 28, 2003 First published online July 25, 2006

\section{REFERENCES}

Albert, M. S., \& Kaplan, E. (1980). Organic Implications of neuropsychological deficits in the elderly. In L. W. Poon, J. L. Fozard, L. S. Cermak, D. Arenberg, \& W. Thompson, (Eds.), New directions in memory and aging: Proceedings of the George A. Talland Memorial Conference (pp. 403-432), Hillsdale, NJ: Erlbaum.

Angioi-Duprez, K., Braun, M., Jonveaux, T., Picard, L., \& George, J. (2000). Exploration of visual memory by functional MRI. Journal Francais d'Opthalmologie, 23, 19-26.

Backman, L., Almkvist, O., Andersson, J., Nordberg, A., Winblad, B., Reineck, R., \& Langstrom, B. (1997). Brain activation in young and older adults during implicit and explicit retrieval. Journal of Cognitive Neuroscience, 9, 378-391.

Backstrom, T., Bixo, M., \& Hammerback, S. (1985). Ovarian steroid hormones: Effects on mood, behavior, and brain excitability. Acta Obstetrica Gynecologica Scandanavica Supplementum, 130, 19-24.

Baddeley, A. D. et al. (1987). Sentence comprehension and phonological memory: Some neuropsychological evidence. In M. Coltheart, (Ed.), Attention and performance, Vol. XII: The psychology of reading (pp. 509-529), Hillsdale, NJ: Lawrence Erlbaum.

Baddeley, A. (2000). Short-term and working memory. In F. I. M. Craik and E. Tulving (Eds.), The Oxford handbook of Memory (pp. 77-92). New York: Oxford University Press.

Barret-Conner, E., \& Kritz-Silverstein, D. (1993). Estrogen replacement therapy and cognitive function in older women. JAMA, 269, 2637-2641.

Benton, A. L., \& Hamsher, K. (1978). Multilingual aphasia examination. Iowa City: University of Iowa.

Berman, K. F., Schmidt, P. J., Wubinow, D. R., Danaceau, M. A., van Horn, J. D., Esposito, G., Ostrem, J. L., \& Weinberger, D. R. (1997). Modulation of cognition-specific cortical 
activity by gonadal steroids: A positron-emission tomography study in women. Proceedings of the National Academy of Science, 94, 8836-8841.

Birge, S. J. (1997). The role of ovarian hormones in cognition and dementia. Journal of the American Academy of Neurology, 48, S1-S41.

Bixo, M., Backstrom, T., Winblad, B., \& Andersson, A. (1995). Estradiol and testosterone in specific regions of the human female brain in different endocrine states. Steroid Biochemical Molecular Biology, 55, 297-303.

Bushke, H., \& Fuld, P. A. (1974). Evaluating storage, retention, and retrieval in disordered memory and learning. Neurology, 24, 1019-1025.

Butters, M. A., Kaszniak, A.W., Glisky, E. L., Eslinger, P. J., \& Schacter, D. L. (1994). Recency discrimination deficits in frontal lobe patients. Neuropsychology, 8, 343-353.

Cabeza, R., Grady, C. L., Nyberg, L., McIntosh, A. R., Tulving, E., Kapur, S., Jennings, J. M., Houle, S., \& Craik, F.I. (1997). Age-related differences in neural activity during memory encoding and retrieval: a positron emission tomography study. Journal of Neuroscience, 17, 391-400.

Caldwell, B., \& Watson, R. (1952). An evaluation of psychologic effects of sex hormone administration in aged women: results after six months. Journal of Gerontology, 7, $228-244$.

Canavan, A. G. M., Passingham, R. E., \& Marsden, C. D. (1989). Sequencing ability in Parkisonians patients with frontal lobe lesions and patients who have undergone unilateral temporal lobectomies. Neuropsychologia, 27, 787-798.

Carlson, L. E., \& Sherwin, B. B. (1998). Steroid hormones, memory and mood in a healthy elderly population. Psychoneuroendocrinology, 23, 583-603.

Cohen, J. (1988). Statistical power analysis for the behavioral sciences. Hillsdale, NJ: Lawrence Erlbaum Associates.

Craik, F. I. M., \& Jennings, J. M. (1992). Human memory. Hillsdale, NJ: Lawrence Erlbaum Associates.

Craik, F. I. M., \& Lockhart, R. (1986). CHARM is not enough: Comments on Eich's model of cued recall. Psychological Review, 93, 360-364.

D’Esposito, M., \& Postle, B. R. (1999). The dependence of span and delayed-response performance on prefrontal cortex. Neuropsychologia, 37, 1303-1315.

D’Esposito, M., Postle, B. R., \& Rypma, B. (2000). Prefrontal cortical contributions to working memory: Evidence from event-related fMRI studies. Experimental Brain Research, 133, 3-11.

Dempster, F. N. (1992). The rise and fall of the inhibitory mechanism: Toward a unified theory of cognitive development and aging. Developmental Review, 12, 45-75.

Ditkoff, E. C., Crary, W. R., Cristo, M., \& Lobo, R. A. (1991). Estrogen improves psychological function in asymptomatic postmenopausal women. Obstetrics \& Gynecology, 78, 991-995.

Duff, S. J., \& Hampson, E. (2000). A beneficial effect of estrogen on working memory in postmenopausal women taking hormone replacement therapy. Hormones and Behavior, $38,262-276$.

Duka, T., Tasker, R., \& McGowan, J. F. (2000). The effects of 3-week estrogen hormone replacement on cognition in elderly healthy females. Psychopharmacology, 149, 129-139.

Egeland, G., Kuller, L., Matthews, K., Kelsey, S., Cauley, J., \& Guzick, D. (1991). Premenopausal determinants of menopausal estrogen use. Preventive Medicine, 20, 343-349.

Fabiani, M., \& Friedman, D. (1997). Dissociations between recency and recognition memory in aging. Journal of Comparative Neurology, 35, 129-141.

Fedor-Freybergh, P. (1977). The influence of oestrogens on the wellbeing and mental performance in climacteric and postmenopausal women. Acta Obstetrica Gynecologica Scandanavica Supplementum, 64, 1-91. 
Fernandez-Duque, D., Baird, J., \& Posner, M. (2000). Executive attention and metacognitive regulation. Consciousness and Cognition: An International Journal, 9, 288-307.

Ferreira, C., Teixeria, C., Verin, M., Anon, J., Levy, R., Dubois, B., \& Agid, Y. (1998). Spatio-temporal working memory and frontal lesions in man. Masson Italia Periodici, Italy, 34, 83-98.

Funahashi, S., Chafee, M.V., \& Goldman-Rakic, P. S. (1993). Prefrontal neuronal activity in rhesus monkeys performing a delayed anti-saccade task. Nature, 365, 753-756.

Funk, J. L., Mortel, K. F., \& Meyer, J. S. (1991). Effects of estrogen replacement therapy on cerebral perfusion and cognition among postmenopausal women. Dementia, 2, 268-272.

Glisky, E. L., Polster, L., \& Routhieaux, B. (1995). Double dissociation between item and source memory. American Psychological Association, 9, 229-235.

Glisky, E. L., Rubin, S. R., \& Davidson, P. S. (2001). Source memory in older adults: an encoding or retrieval problem? Journal of Experimental Psychology: Learning, Memory and Cognition, 27, 1131-1146.

Grafman, J., Jonas, B., \& Salazar, A. (1990). Wisconsin Card Sorting Test performance based on location and size of neuroanatomical lesion in Vietnam veterans with penetrating head injury. Perceptual and Motor Skills, 71, 1120-1122.

Gron, G. (1998). Auditory and visual working memory performance in patients with frontal lobe damage and in schizophrenic patients with low scores on the Wisconsin Card Sorting Test. Psychiatry Research, 80, 83-96.

Gurland, B., Golden, R. R., Teresi, J. A., \& Challop, J. (1984). The SHORT-CARE: An efficient instrument for the assessment of depression, dementia and disability. Journal of Gerontology, 39, 166-169.

Hackman, B. W., \& Galbraith, D. (1977). Six month study of oestrogen therapy with piperazine oestrone sulphate and its effects on memory. Current Medical Research Opinion, 4, 21-27.

Heaton, R. K. (1981). Wisconsin Card Sorting Test (WCST). Odessa, FL: Psychological Assessment Resources.

Henson, R., Shallice, T., \& Dolan, R. (2000). Neuroimaging evidence for dissociable forms of repetition priming. Science, 287, 1269-1272.

Hogervorst, E., Boshuisen, M., Riedel, W., Willekien, C., \& Jolles, J. (1999). The effect of hormone replacement therapy on cognitive function in elderly women. Psychoneuroendocrinology, 24, 43-68.

Hollingshead, A. B., \& Redlich, F. C. (1958). Social class and mental illness. New York: Wiley.

Howard, D. V., Heisey, J. G., \& Shaw, R. J. (1986). Aging and the priming of newly learned associations. Developmental Psychology, 22, 78-85.

Jacobs, D., Tang, M.-X., Stern, Y., Sano, M., Marder, K., Bell, K. L., Schofield, P., Dooneief, G., Gurland, B., \& Mayeux, R. (1998). Cognitive function in nondemented older women who took estrogen after menopause. Neurology, 50, 368-373.

Jacoby, L. L. (1991). A process dissociation framework: Separating automatic from intentional uses of memory. Journal of Memory and Language, 30, 513-541.

Janowsky, J., Shimamura, A. P., Kritchevsky, M., \& Squire, L. (1989a). Cognitive impairment following frontal lobe damage and its relevance to human amnesia. Behavioral Neuroscience, 103, 548-560.

Janowsky, J., Shimamura, A. P., \& Squire, L. R. (1989b). Source memory impairment in patients with frontal lobe lesions. Neuropsychologia, 27, 1043-1056.

Janowsky, J. S., Carello, P., \& Orwoll, E. (1999). Progesterone reverses estrogen's enhancement of verbal memory. Society for Neuroscience Abstracts, 25, 1062.

Johnson, M. K., Hashtroudi, S., \& Lindsay, D. (1993). Source monitoring. Psychological Bulletin, 114, 3-28. 
Johnson, M. K., O’Connor, M., \& Cantor, J. (1997). Confabulation, memory deficits, and frontal dysfunction. Brain and Cognition, 34, 189-206.

Kampen, D. L., \& Sherwin, B. B. (1994). Estrogen use and verbal memory in healthy postmenopausal women. Obstetrics \& Gynecology, 83, 979-983.

Kausler, D. H., Salthouse, T. A., \& Saults, J. S. (1988). Temporal memory over the adult lifespan. American Journal of Psychology, 101, 207-215.

Keenan, P. A., Ezzat, W. H., Ginsburg, K., \& Moore, G. J. (2001). Prefrontal cortex as the site of estrogen's effect on cognition. Psychoneuroendocrinology, 26, 577-590.

Kimura, D. (1995). Estrogen replacement therapy may protect against intellectual decline in postmenopausal women. Hormones and Behavior, 29, 312-321.

Kritzer, M. F., \& Kohama, S. G. (1998). Ovarian hormones influence the morphology, distribution, and density of tyrosine hydroxylase immunoreactive axons in the dorsolateral prefrontal cortex of adult rhesus monkeys. Journal of Comparative Neurology, 395, 1-17.

Kritzer, M. F., \& Kohama, S. G. (1999). Ovarian hormones differentially influence immunoreactivity for dopamine b-hydroxylase, choline acetyltransferase, and serotonin in the dorsolateral prefrontal cortex of adult rhesus monkeys. Journal of Comparative Neurology, 409, 438-451.

Larrabee, G. J., Trahan, D. E., Curtiss, G., \& Levin, H.S. (1988). Normative data for the verbal Selective Reminding Test. Neuropsychology, 2, 173-182.

LeBlanc, E. S., Janowsky, J., Chan, B. K. S., \& Nelson, H. D. (2001). Hormone replacement therapy and cognition. JAMA, 285, 1489-1499.

Lindman, H. (1974). Analysis of variance in complex experimental designs. San Francisco: W.H. Freeman and Co.

Luine, V. N. (1985). Estradiol increases choline acetyltransferase activity in specific basal forebrain nuclei and projection areas of female rats. Experimental Neurology, 89, 484-490.

Madden, D. J., Gottlob, L. R., \& Coleman, R. E. (1999). Aging and recognition memory: Changes in regional cerebral blood flow associated with components of reaction time distributions. 11(5), 511-520.

Maki, P. M., Zonderman, A. B., \& Resnick, S. M., 2001. Enhanced verbal memory in nondemented elderly women receiving hormone-replacement therapy. American Journal of Psychiatry, 158, 227-233.

Mangels, J., 1997. Strategic processing and memory for temporal order in patients with frontal-lobe lesions. Neuropsychology, 11, 1-15.

Matthews, K., Kuller, L., Wing, R., Meilahn, E., \& Plantinga, P. (1996). Prior to use of estrogen replacement therapy, are users healthier than nonusers? American Journal of Epidemiology, 143, 971-978.

Mayeux, R., Stern, Y., Rosen, J., \& Levethal J. (1981). Depression, intellectual impairment and Parkinson's disease. Neurology, 31, 645-650.

McDowd, J. M., Joan, M., \& Shaw, R. J. (2000). Attention and aging: A functional perspective. In T. A. Salthouse \& F.I . M. Craik (Eds.), The handbook of aging and cognition (pp. 221-292). Mahwah, NJ: Lawrence Erlbaum Associates, Inc.

McEwen, B. S., Gerlach, J. L., Luine, V. N., \& Leinberburg, J. (1977). Neural steroid hormone receptors. Psychoneuroendocrinology, 2, 249-255.

McIntyre, J. S., \& Craik, F. I. M. (1987). Age differences in memory for item and source information. Canadian Journal of Psychology, 41, 175-192.

McKoon, G., \& Ratcliff, R. (1979). Priming in episodic and semantic memory. Journal of Verbal Learning and Verbal Behavior, 18, 463-480.

Milner, B. (1963). Effects of different brain lesions on card sorting. Archives of Neurology, 9, 90-100. 
Milner, B., Corsi, P., \& Leonard, G. (1991). Frontal lobe contribution to recency judgements. Neuropsychologia, 29, 601-618.

Miyake, A., Friedman, N., Rettinger, D., Shah, P., \& Hegarty, M. (2001). How are visuospatial working memory, executive functioning, and spatial abilities related? A latent-variable analysis. American Psychological Association, 130, 621-640.

Moscovitch, M. (1994). Memory and working with memory: Evaluation of a component process model and comparison with other models. In D. L. Schacter \& E. Tulving (Eds.), Memory systems 1994 (pp. 269-310). New York: Oxford University Press.

Moscovitch, M., \& Winocur, G. (1992). The neuropsychology of memory and aging. In T. A. Salthouse \& F. I. M. Craik (Eds.), The handbook of aging and cognition (pp. 315-372). Hillsdale, NJ: Lawrence Erlbaum Associates, Inc.

Nagahama, Y., Fukuyama, H., Yamauchi, H., Katsumi, Y., Magata, Y., Shibasaki, H., \& Kimura, J. (1997). Age-related changes in cerebral blood flow activation during a card sorting test. Experimental Brain Research, 114, 571-577.

Nolde, S., Johnson, M. K., \& D’Esposito, M. (1998). Left prefrontal activation during episodic remembering: An event-related fMRI study. Neuroreport, 9, 3509-3514.

Nyberg, L., McIntosh, A. R., Cabeza, R., Habib. R., Houle, S., \& Tulving, E. (1996). General and specific brain regions involved in encoding and retrieval of events: What, where, and when. Proceedings of the National Academy of Sciences, 93, 11280-11285.

Ohkura, T., Isse, K., Akazawa, K., Hamamoto, M., Yaoi, Y., \& Hagino, N. (1995). Long-term estrogen replacement therapy in female patients with dementia of the Alzheimer type: 7 case reports. Dementia, 6, 99-107.

Parkin, A. J., Hunkin, N. M., \& Walter, B. M. (1995). Relationships between aging, frontal lobe function, and memory for temporal and spatial information. Neuropsychology, 9, 304-312.

Petrides, M. (1991). Functional specialization within the dorsolateral frontal cortex for serial order memory. Proceedings of the Royal Society of London, Series B, 246, 299-306.

Phillips, S. M., \& Sherwin, B. B. (1992). Effects of estrogen on memory function in surgically menopausal women. Pyschoneurendocrinology, 17, 485-495.

Polo-Kantola, P., Portin, R., Polo, O., Helenius, H., Irjala, K., \& Erkkola, R. (1998). Effect of short-term estrogen replacement therapy on cognition: A randomized, double-blind, crossover trail in postmenopausal women. Obstetrics \& Gynecology, 91, 459-466.

Poon, L. W., \& Fozard, J. L. (1980). Age and word frequency effects in continuous recognition memory. Journal of Gerontology, 35, 77-86.

Purdy, R. H., Moore, P. H. R. P. M., Hagino, N., Yamaguchi, T., Schmidt, P., Rubinow, D. R., Morrow, A., \& Paul, S. M. (1990). Radioimmunoassay of 3 alpha hydroxy-5-alphapregaine-20-one in rat and human plasma. Steroids, 55, 290-296.

Raz, N., Gunning-Dixon, F.M., Head, D. P., Dupuis, J. H., \& Acker, J. D. (1998). Neuroanatomical correlates of cognitive aging: Evidence from structural MRI. Neuropsychology, $12,95-114$.

Resnick, S. M., Maki, P. M., Golski, S., Kraut, M. A., \& Zonderman, A. B. (1998). Effects of estrogen therapy on PET cerebral blood flow and neuropsychological performance. Hor mones and Behavior, 34, 171-182.

Rice, M. M., Graves, A. B., McCurry, S. M., Gibbons, L. E., Bowen, J. D., McCormick, W. C., \& Larson, E. B. (2000). Postmenopausal estrogen and estrogen-progestin use and 2year rate of cognitive change in a cohort of older Japanese American women. Archives of Internal Medicine, 160, 1641-1649.

Rice, M. M., Graves, A. B., McCurry, S. M., \& Larson, E. B. (1997). Estrogen replacement therapy and cognitive function in postmenopausal women without dementia. American Journal of Medicine, 103, 26S-35S.

Robinson, D., Friedman, D., Marcus, R., Tinklenberg, J., \& Yesavage, J. (1994). Estrogen replacement therapy and memory in older women. JAGS, 42, 919-922. 
Rugg, M. D., Fletcher, P. C., Chua, P., \& Dolan, R. J. (1999). The role of the prefrontal cortex in recognition memory and memory for source: An fMRI study. Neuroimage, 10, 520-529.

Salthouse, T. A. (1990a). Influence of experience on age differences in cognitive functioning. Human Factors, 32, 551-569.

Salthouse, T. A. (1990b). Working memory as a processing resource in cognitive aging. Developmental Review, 10, 101-124.

Sarrel, P. M. (1990). Ovarian hormones and the circulation. Maturitas, 590, 287-298.

Schechter, D., Bachmann, G.A., Vaitukaitis, J., Phillips, D., \& Saperstein, D. (1989). Perimenstrual Distress: Variations in phenomenology, severity, and time course. Psychosomatic Medicine, 5, 173-194.

Schloesser, R., Hutchinson, M., Joseffer, S., Rusinek, H., Saarimaki, A., Stevenson, J., Dewey, S., \& Brodie, J. (1998). Functional magnetic resonance imaging of human brain activity in a verbal fluency task. Journal of Neurology, Neurosurgery \& Psychiatry, 64, 492-498.

Schmidt, R., Fazekas, F., Reinhart, B., Kapeller, P., Fazekas, G., Offernbacher, H., Eber, B., Schumacher, M., \& Freidl, W. (1996). Estrogen replacement therapy in older women: A neuropsychological and brain MRI study. JAGS, 34, 1307-1313.

Shaywitz, S.E., Shyawitz, B.A., Pugh, K.R., Fulbright, R.K., Skudlarski, P., Menel, W.E., Constable, R.T., Naftolin, F., Plater, S.F., Marchione, K.E., Katz, L., Shankwieler, D.P., Fletcher, J.M., Lacadie, C., Keltz, M., \& Gore, J.C. (1999). Effects of estrogen on brain activation patterns in postmenopausal women during working memory tasks. JAMA, 281, 1197-1202.

Sherwin, B.B. (1988). Estrogen and/or androgen replacement therapy and cognitive functioning in surgically menopausal women. Psychoneuroendocrinology, 13, 345-357.

Sherwin, B.B. (1991). The impact of different doses of estrogen and progestin on mood and sexual behavior in postmenopausal women. Journal of Clinical Endocrinology and Metabolism, 72, 336-343.

Shimamura, A.P. (1996). The role of prefrontal cortex in controlling and monitoring memory processes. In L. Reder (Ed.), Implicit memory and metacognition. Mahwah, NJ: Erlbaum.

Singh, M., Meyer, E.M., Millard, W.J., \& Simpkins, J.W. (1994). Ovarian steroid deprivation results in a reversible learning impairment and compromised cholingeric function in female Sprague-Dawley rats. Brain Research, 644, 305-312.

Smith, M.E., \& Halgren, E. (1989). Dissociation of recognition memory components following temporal lobe lesions. Journal of Experimental Psychology: Learning, Memory and Cognition, 15, 50-60.

Snodgrass, J.G., \& Corwin, J. (1988). Pragmatics of measuring recognition memory: Application to dementia and amnesia. Journal of Experimental Psychology: General, 117, 34-50.

Spencer, W., \& Raz, N. (1995). Differential effects of aging on memory for content and context: A meta-analysis. Psychology and Aging, 10, 527-539.

Spreen, O., \& Strauss, E. (1998). A compendium of neuropsychological tests. New York: Oxford University Press.

Squire, L. (1987). Memory and brain. New York: Oxford University Press.

Stuss, D.T., Craik, F.I.M., Franchi, D., \& Alexander, M.P. (1996). Comparison of older people and patients with frontal lesions: evidence from world list learning. Psychology and Aging, 11, 387-395.

Stuss, D.T., \& Levine, B. (2002). Adult clinical neuropsychology: Lessons from studies of the frontal lobes. Annual Review of Psychology, 53, 401-403.

Stuss, D.T., Shallice, T., Alexander, M.P., \& Picton, T.W. (1995). A multidisciplinary approach to anterior attentional functions. Annals New York Academy of Sciences, 769, 191-211.

Summer, B.E., \& Fink, G. (1995). Estrogen increases the density of 5-hydroxytryptamine(2A) receptors in cerebral cortex and nucleus accumbens in the female rat. Journal of Steroid Biochemistry and Molecular Biology, 54, 15-20. 
Tomer, R., \& Levin, B. (1993). Differential effects of aging on two verbal fluency tasks. Perceptual \& Motor Skills, 76, 465-466.

Trott, C., Friedman, D., Ritter, W., \& Fabiani, M. (1999). Episodic priming and memory for temporal source: Event-related potentials reveal age-related differences in prefrontal function. Psychology and Aging, 14, 390-413.

Tsukiura, T., Fujii, T., Takahashi, T., Xiao, R., Inase, M., Iijima, T., Yamadori, A., \& Okuda, J. (2001). Neuroanatomical discrimination between manipulating and maintaining processes involved in verbal working memory; a functional MRI study. Cognitive Brain Research, $11,13-21$.

Ullman, M.T. (2001). A neurocognitive perspective on language: The declarative/procedural model. Nature Reviews Neuroscience, 2, 717-726.

Verin, M., Partiot, A., Dillon, B., \& Malapani, C. (1993). Delayed response tasks and prefrontal lesions in man: Evidence for self-generated patterns of behavior with poor environmental modulation. Neuropsychologia, 31, 1379-1396.

Wechsler, D. (1981). Wechsler Memory Scale-revised. San Antonio, TX: Psychological Corporation.

Wechsler, D. (1997). Wechsler Memory Scale-III. San Antonio, TX: Psychological Corporation.

Wegesin, D.J., Jacobs, D., Zubin, N.R., Ventura, P.R., \& Stern, Y. (2000). Source memory and encoding strategy in normal aging. Journal of Clinical and Experimental Neuropsychology, 22, 455-464.

Wegesin, D.J., Friedman, D., Varughese, N., \& Stern, Y. (2002). Age-related changes in source memory retrieval: An ERP replication and extension. Cognitive Brain Research, 13, 323-338.

West, R. (1996). An application of prefrontal cortex function theory to cognitive aging. Psychological Bulletin, 120, 272-292.

Wheeler, M.A., Stuss, D.T., \& Tulving, E. (1995). Frontal lobe damage produces episodic memory impairment. Journal of the International Neuropsychological Society, $1,525-536$.

Wilson, B., \& Baddeley, A. (1988). Semantic, episodic, and autobiographical memory in a postmeningitic amnesic patient. Brain and Cognition, 8, 31-46.

Woolley, C.S., \& McEwen, B.S. (1993). Roles of estradiol and progesterone in regulation of hippocampal dendritic spine density during the estrous cycle in the rat. Journal of Comparative Neurology, 336, 293-306.

Yaffe, K., Sawaya, G., Lieberburg, I., \& Grady, D. (1998). Estrogen therapy in postmenopausal women: Effects on cognitive function and dementia. JAMA, 279, 688-695.

Zelinski, E.M., \& Light, L. (1988). Young and older adult's use of context in spatial memory. Psychology and Aging, 3, 99-101.

Zysset, S., Muller, K., Lehmann, C., Thone-Otto, A., \& von Cramon, D. (2001). Retrieval of long and short lists from long term memory: A functional magnetic resonance imaging study with human subjects. Neuroscience Letters, 314, 1-4. 